\title{
Isolation of Edwardsiella ictaluri from channel catfish by tissue homogenization, filtration and enzyme linked immunosorbent assay
}

\author{
Dean Earlix, John A. Plumb*, W. A. Rogers \\ Department of Fisheries and Allied Aquacultures, Auburn University, Auburn, Alabama 36849, USA
}

\begin{abstract}
An enzyme linked immunosorbent assay (ELISA) was developed to detect and quantify Edwardsiella ictaluri in asymptomatic carrier channel catfish Ictalurus punctatus and was compared to conventional culture on agar. Tissue homogenization, using $0.5 \%$ Triton X-100 in $0.05 \mathrm{M}$ phosphate buffered saline ( $\mathrm{pH} 7.2$ ), clarified tissue slurries, improved filterability and permitted live bacteria to be filtered from $1 \mathrm{~g}$ or more of channel catfish organ tissue. Treatment of tissues with Tween 20 or trypsin did not allow improved filtration or bacterial counts. Bacteria captured on $0.45 \mu \mathrm{m}$ nitrocellulose membrane filters were cultured on E. ictaluri medium agar Bacterial colonies on the filters were tagged with a monoclonal antibody to E. ictaluri on which an ELISA was performed. The ELISA substrate 3,3'diaminobenzidine facilitated rapid bacterial colony forming unit (CFU) counts without magnification, permitted semipermanent records of isolations, and enabled microscopic confirmation following mounting with Permount. Assay sensitivity was less than $10 \mathrm{CFU} \mathrm{g}^{-1}$ of tissue. Conventional bacterial isolation and filter ELISA screening of 98 channel catfish from a population experiencing an outbreak of enteric septicemia of catfish (ESC) showed an infection prevalence of $24 \%$ by standard bacterial isolation techniques and $80 \%$ by filter ELISA in asymptomatic fish.
\end{abstract}

KEY WORDS: Edwardsiella ictaluri Bacterial detection - Channel catfish

\section{INTRODUCTION}

Edwardsiella ictaluri, the causative agent of enteric septicemia of catfish (ESC), has spread to virtually all geographic regions where channel catfish Ictalurus punctatus are cultured. The transport of asymptomatically infected carriers has been implicated in the spread of ESC even into areas where programs have been in place to prevent importation and spread of diseased catfish (MacMillan 1985, Taylor 1992, Chen et al. 1994). In view of the probable spread of E. ictaluri in covert carriers there is a need for improved bacterial detection procedures for this pathogen.

The most economical, effective, nonlethal means of screening fish populations for exposure to a pathogen is serum-specific antibody testing. An unequivocally positive antibody titer does not necessarily accompany

\footnotetext{
-Addressee for correspondence.
}

E-mail:jplumb@ag.auburn.edu infection (Klesius 1992); therefore, the presence of positive antibady against Edwardsiella ictaluri, without isolation of the pathogen, has uncertain implications. Thus, isolation of bacteria from fish remains the only definitive means of detecting infections with $E$. ictaluri. Fish health certification procedures outlined by the American Fisheries Society recommends conventional bacteriological isolation of $E$. ictaluri for disease screening (Shotts \& Plumb 1994).

Asymptomatically infected channel catfish may appear normal and test negative for Edwardsiella ictaluri by conventional bacteriological necropsy techniques. Juvenile channel catfish tested by Klesius (1992) appeared healthy, but $E$. ictaluri could be isolated following organ disruption and in vitro amplification of bacterial abundance by broth enrichment. Antonio \& Hedrick (1994) showed that, whereas bacteria could not be recovered from an apparently healthy channel catfish 4 mo after experimental infection, injection with the corticosteroid Kenalog enabled isolation of 
E. ictaluri from the formerly asymptomatic fish. No isolation protocol has successfully quantified $E$. ictaluri in tissues of naturally infected fish or accurately determined infection prevalence within a fish population.

Edwardsiella ictaluri was quantified in tissues by inoculating agar with tissue slurries (Shotts et al. 1986 , Mgolomba \& Plumb 1992), but inoculum volume was limited by slurry viscosity and absorptive capacity of the agar. Filtration of tissues reduces absorption limits of culture media and enables direct bacterial cell counts. The detection threshold of microscopic observation is often limited by masking growth of less fastidious organisms (Jones \& Simon 1975), E. ictaluri for example, filter clogging (Lee 1989), and the relatively large number of bacteria that must be captured to appear in a viewing field at high magnification (Wiebe 1971).

In the current study, bacterial isolation and filter enzyme linked immunosorbent assay (ELISA) is described and evaluated for the detection of Edwardsiella ictaluri in the tissues of asymptomatic channel catfish and those experiencing overt infection. A comparison between conventional agar screening techniques and filter ELISA was conducted to evaluate relative detection sensitivity.

\section{MATERIALS AND METHODS}

Homogenization. Homogenization treatments adapting ELISA to detect Edwardsiella ictaluri in fish tissues were drawn from the work of Lee (1989). The liver, trunk kidney and spleen of individual fish were combined and homogenized in sterile $50 \mathrm{ml}$ conical centrifuge tubes with a Kinematica Polytron (Brinkman Instruments, Westbury, New York) tissue homogenizer. Homogenization was performed for $15 \mathrm{~s}$ at speed setting 5 and continued for $30 \mathrm{~s}$ at speed setting 7. The homogenization probe was disinfected and cleaned between samples by dipping in 70\% isopropanol for $30 \mathrm{~s}$, tissue strands removed with forceps and the probe rinsed in sterile distilled water.

Filtration. Treatments using an enzyme and detergent as diluents alone and in combination were evaluated for their ability to increase the quantity of homogenized tissue passing through membrane filters. Phosphate buffered saline (0.05 M PBS, pH 7.2) was utilized as a baseline treatment and supplemented with $0.05,0.50$, and $1.0 \%(\mathrm{v} / \mathrm{v})$ of Tween 20 (Sigma, St. Louis, Missouri) with identical concentrations of the non-ionic surfactant Triton X-100 (Sigma); 0.013, 0.13, and $1.25 \%(\mathrm{w} / \mathrm{v})$ of trypsin (Type III, Sigma) and one treatment solution of $0.25 \%$ trypsin combined with $0.25 \%$ Triton. Each detergent and trypsin solution was prepared at double strength and mixed $1: 1(\mathrm{v} / \mathrm{v})$ with tissues for homogenization. Following homogenization all organ slurries were diluted in PBS to provide $0.25 \mathrm{~g}$ tissue $\mathrm{ml}^{-1}$. These solutions stood at room temperature for $1 \mathrm{~min}$, then in $200 \mu$ portions, were vacuum inoculated with a micropipet onto $85 \mathrm{~mm}, 0.45 \mu \mathrm{m}$ pore nitrocellulose filters until. they clogged (Earlix 1995). Inoculated filters were then aseptically transferred face up onto dried (approximately 90\% moisture) Edwardsiella ictaluri isolation media (EIM) (Shotts \& Waltman 1990 ) and incubated for $24 \mathrm{~h}$ at $25^{\circ} \mathrm{C}$. During 3 experimental runs, each filter was processed for ELISA (described below).

Change in bacterial abundance resulting from homogenization treatment and storage was evaluated using infected liver tissue from yearling channel catfish injected with nonpathogenic Edwardsiella ictaluri 11 and $14 \mathrm{~d}$ previously. A non-virulent strain was used because death of experimental fish was undesirable. Values from a preliminary trial were used to determine the weights of tissue required to yield about 5000 colony forming units (CFU) of E. ictaluri per gram. Using these values, putatively infected liver was aseptically transferred to $1: 10(\mathrm{w} / \mathrm{v})$ in PBS (approximately $500 \mathrm{CFU} \mathrm{ml}^{-1}$ ) and homogenized. Homogenized tissue was added to equal volumes of double-strength PBSdetergent and enzyme treatment solutions to yield $0.1,0.25$, and 0.5 trypsin; $0.1,0.25$, and 0.5 Triton $X-100$; $0.25 \%$ trypsin plus $0.25 \%$ Triton, and PBS without supplement. Homogenized treatment solutions were allowed to stand for $2,3,4$ and $5 \mathrm{~h}$, at which times they were again diluted 10 - and 100-fold in sterile PBS before spread plating onto quadruplicate EIM agar plates for enumeration.

Enzyme linked immunosorbent assay evaluation. Filter ELISA labeling modifications were evaluated to accommodate the wide range of bacterial abundance in the tissues of infected fish. Four $85 \mathrm{~mm}$ diameter nitrocellulose filters $(0.45 \mu \mathrm{m}$ porosity) were each inoculated by vacuum filtration with $1 \mathrm{ml}$ of 10 -fold serial dilutions from $10^{-1}$ to $10^{-6}$ of Edwardsiella ictaluri in PBS. Each filter was removed from the filtration device and incubated face up on EIM agar for 24 h at $25^{\circ} \mathrm{C}$. An additional 24 filters were inoculated with approximately $10^{3} \mathrm{CFU}$ of Edwardsiella tarda and cultured as a negative control for the assay procedure; E. ictaluri treatments constituted their own positive control. All filters were removed from agar after culture, incubated $1 \mathrm{~h}$ at room temperature with gentle shaking in Petri. dishes filled with $10 \mathrm{ml}$ blocking solution [PBS $+10 \%$ (v/w) nonfat dry milk and $0.2 \%$ (v/v) Tween 20), and washed 15 min with shaking in PBS $+0.05 \%$ Tween 20. One negative control filter (E. tarda) was added to each treatment dish and processed as for E. ictaluri filters. Two filters with each E. ictaluri serial 10 -fold dilution were incubated $1 \mathrm{~h}$ with shaking in $10 \mathrm{mI}$ single or 
double strength primary antibody (1:100 or 1:50) anti E. ictaluri hybrodoma supernatant 9G4-D9 in PBS (Earlix 1995) then washed $3 x$ in PBS without Tween 20. One of each antigen-primary antibody treatment pair was then incubated $1 \mathrm{~h}$ with shaking in $10 \mathrm{ml}$ single or double strength secondary antibody (1:2000 or 1:1000 rabbit anti mouse IgG conjugated to horseradish peroxidase diluted in PBS; Sigma) then washed $3 \times$ and rinsed in PBS. Filters were quartered and one portion of each incubated 10 min with shaking in $10 \mathrm{ml}$ of either 3, 3'diaminobensidine (DAB; Sigma) or $20 \mathrm{~min}$ in 4-chloro-1-naphthol (4CIN; Sigma), each mixed at $1 \times$ or $2 \times$ recommended strength. The shorter incubation time for DAB was because of its greater sensitivity to horseradish peroxidase. The 96 membrane quarters and negative controls were dried and examined to determine which reagents enabled optimum positive staining of the widest range of E. ictaluri bacterial concentrations while minimizing nonspecific staining of $E$. tarda colonies. The trial was repeated without replication for bacterial incubation periods of 36 and $48 \mathrm{~h}$ at room temperature.

Microscopic confirmation of stained and unstained colonies was carried out. Circular, $5 \mathrm{~mm}$ filter sections including a positively stained colony were separated by hole punch (Earlix 1995), placed on a microscope slide with $100 \mathrm{\mu l}$ Permount, which cleared the filter paper, and then a cover slip applied. After drying, transparent membranes were examined under oil immersion $(1000 \times)$ to evaluate stain performance.

Comparison of agar plating and filter ELISA. Ninety-eight 1 yr old channel catfish were randomly collected from 5 net cages in a 11 ha pond in which clinical ESC was in progress. Each fish was examined for clinical signs of ESC. The trunk kidney of each fish was aseptically exposed with a longitudinal abdominal incision, a loop full of trunk kidney tissue inoculate was placed on to an EIM agar plate, and about $1 \mathrm{~g}$ of the organ was aseptically transferred into a sterile $50 \mathrm{ml}$ conical centrifuge tube with $5 \mathrm{ml}$ homogenization solution. It was shown by Earlix (1995) that storage of Edwardsiella ictaluri in ice water for up to $4 \mathrm{~h}$ did not reduce bacterial populations; therefore, tissue was held between 0 and $4{ }^{\circ} \mathrm{C}$ until processed (less than $3 \mathrm{~h}$ ) and analyzed using the filtration methods found optimal through trials described above.

\section{RESULTS}

\section{Homogenization and filtration}

Because of the variation in filtration volumes, treatment effects of detergents and enzyme are reported only qualitatively (Table 1). Homogenization with PBS
Table 1 Qualitative evaluation of homogenate filterability and bacterial viability associated with homogenization and digestion treatments using phosphate buffered saline (PBS) control, Triton X-100, Tween 20 and trypsin, and a combination of Triton + trypsin. Rating of subjective performance: $-=$ no data $_{+}+=$poor performance $;+=$moderate performance; $+++=$ acceptable performance $++++=$ best performance

\begin{tabular}{lcc}
\cline { 2 - 3 } Treatment & $\begin{array}{c}\text { Homogenate } \\
\text { filterability }\end{array}$ & $\begin{array}{c}\text { Bacterial } \\
\text { viability }\end{array}$ \\
\hline PBS & + & ++++ \\
$0.05 \%$ Triton $X-100$ & ++++ & +++ \\
$0.5 \%$ Triton $X-100$ & ++++ & +++ \\
$1.0 \%$ Triton $X-100$ & ++ & - \\
0.05 Tween 20 & + & - \\
$0.5 \%$ Tween 20 & +++ & +++ \\
$1.0 \%$ Tween 20 & ++ & ++++ \\
$0.013 \%$ trypsin & + & - \\
$0.13 \%$ trypsin & + & ++++ \\
$1.25 \%$ trypsin & + & + \\
$0.25 \%$ Triton $+0.25 \%$ trypsin & ++++ & ++ \\
\hline
\end{tabular}

yielded poor filterability during the first replicate run, but improved slightly in subsequent runs. Tissues homogenized in $0.5 \%$ or more of Triton X-100 became clear within $1 \mathrm{~min}$ of homogenization and demonstrated excellent filterability, but excessive foam in greater concentrations of Triton limited actual tissue recovery. Tissue homogenized in Tween 20 filtered slightly better than PBS or trypsin-homogenized samples, but never clarified. Homogenization using the 3 higher concentrations of trypsin decreased the filterability during the first trial run; otherwise it performed similarly to PBS. Combinations of Triton and trypsin matched the filterability of detergent alone.

A large range of bacterial concentrations occurred in organ tissues. To obtain usable bacterial abundance data, a 2-way factorial trial examining homogenization treatment and time was collapsed to a 1-way trial by averaging the homogenization treatments over time (Table 2). Observations were normalized by expressing each treatment relative to PBS controls in order to account for bacterial recovery over time. Statistical analysis was not performed because the comparisons were not planned and normalization artificially suppressed abundance variability. The most preferred homogenization treatment depended on a balance between tissue filterability and bacterial viability; both criteria were optimized using $0.5 \%$ Triton X-100 (Tables $1 \& 2$ ).

\section{Enzyme linked immunosorbent assay}

All concentrations of bacteria, including cultures grown to confluence on the agar medium, stained 
Table 2. Recovery of Edwardsiella ictaluri from infected channel catfish liver tissues 2 to $5 \mathrm{~h}$ following $30 \mathrm{shomogenization}$ in phosphate buffered saline (PBS) supplemented with Triton X-100 or trypsin, expressed as a percent of recovery from unsupplemented PBS as the baseline for each sampling period Each value is the mean of 4 replicates

\begin{tabular}{|c|c|c|c|c|c|}
\hline \multirow{2}{*}{ Treatment } & \multicolumn{4}{|c|}{ Percent recovery/storage time (h) } & \multirow{2}{*}{$\begin{array}{l}\text { Aver } \\
\text { age }\end{array}$} \\
\hline & 2 & 3 & 4 & 5 & \\
\hline PBS & 100.0 & 100.0 & 100.0 & 100.0 & 100.0 \\
\hline $0.1 \%$ Triton $\mathrm{X}-100$ & 107.3 & 70.0 & 76.3 & 102.3 & 89.0 \\
\hline $0.25 \%$ Triton $X-100$ & $0 \quad 109.0$ & 76.8 & 87.9 & 89.6 & 90.8 \\
\hline $0.5 \%$ Triton $X-100$ & 112.4 & 95.9 & 82.0 & 97.1 & 96.9 \\
\hline $0.1 \%$ trypsin & 86.6 & 59.9 & 73.2 & 64.0 & 70.9 \\
\hline $0.25 \%$ trypsin & 73.5 & 51.6 & 67.6 & 65.1 & 64.4 \\
\hline $0.5 \%$ trypsin & 56.7 & 36.9 & 33.3 & 33.2 & 40.0 \\
\hline $\begin{array}{l}0.25 \% \text { Triton }+ \\
0.25 \% \text { trypsin }\end{array}$ & 76.5 & 40.5 & 48.9 & 53.0 & 54.8 \\
\hline
\end{tabular}

well using both single- and double-strength DAB substrate (data not shown). False positive staining of Edwardsiella tarda was judged likely using double-strength secondary antibody; therefore, singlestrength DAB substrate and single-strength secondary antibody were determined optimal (Table 3). The 4 CIN system using 1:100 primary antibody and 1:1000 secondary antibody $(2 \times)$ was not as sensitive as the $\mathrm{DAB}$ in detecting lower concentrations of bacteria. Also, the doubling secondary antibody concentration in conjunction with both substrates created intermediate or false positive results for $E$. tarda negative controls. Therefore, doubling primary antibody concentrations provided no observable improved effect over single-strength antibody for any incubation period.
Table 4. Frequency of isolation of Edwardsiella ictaluri from asymptomatic channel catfish on E. ictaluri isolation media (EIM) by conventional isolation methods and compared colony fomring units (CFU) to filter enzyme linked immunosorbent assay (ELISA)

\begin{tabular}{|lccc|}
\hline \multicolumn{2}{c}{ EIM isolation } & \multicolumn{2}{c|}{ Filter ELISA } \\
$\begin{array}{l}\text { Subjective } \\
\text { evaluation }\end{array}$ & No. of fish & $\begin{array}{c}\text { CFU } \text { g }^{-1} \\
\text { of tissue }\end{array}$ & No. of fish \\
\hline None & 68 & None & 17 \\
Light & 13 & $1-10$ & 11 \\
Moderate & 4 & $10-100$ & 12 \\
Heavy & 4 & $100-1000$ & 16 \\
& & $>1000$ & 33 \\
No. positive & $21(24 \%)$ & & $71(80 \%)$ \\
\hline
\end{tabular}

Under microscopic examination 4CIN quickly leached from bacterial cells; however, DAB was resistant to leaching. Stain density of Edwardsiella ictaluri cells trapped on and within the nitrocellulose matrix, as well as positively stained extracellular proteins, apparently bound to the matrix, created a diffuse ring around stained colonies. Colonies of E. ictaluri incubated on filters $36 \mathrm{~h}$ or longer could be identified rapidly and accurately by viewing this ring with transmitted light from a Quebec dark field colony counter. Much lower microscopic grid counts were necessary for filters incubated 24 h with DAB.

\section{Comparison of agar plating and ELISA}

Nine of the 98 channel catfish sampled from the infected population exhibited classical clinical signs of ESC, including petechial hemorrhage along the lateral

Table 3. Filter enzyme linked immunosorbent assay (ELISA) labeling intensity in response to varying antigen concentration following exposure to 1:100 primary monoclonal antibody to Edwardsiella ictaluri, incubation for up to 48 h in 1:2000 (1x) or 1:1000 $(2 \times)$ secondary antibody $\left(2^{\circ} \mathrm{AB}\right)$ and staining with 4 -chloro- 1 napthol $(4 \mathrm{CIN})$ or $3,3^{\prime}$ diaminobenzidine (DAB). CFU: colony forming units. Level of staining response: $-=$ no response with possible slight background ${ } \pm=$ weak positive ELISA response $i+=$ definitive positive ELISA response

\begin{tabular}{|c|c|c|c|c|c|c|c|c|c|}
\hline \multirow[t]{2}{*}{ Stain } & \multirow{2}{*}{$\begin{array}{l}\text { Time } \\
\text { (h) }\end{array}$} & \multirow[t]{2}{*}{$2^{\circ} \mathrm{AB}$} & \multicolumn{6}{|c|}{ ELISA response to E. Ictaluri $\mathrm{CFU} \mathrm{m}^{-1}$} & \multirow[t]{2}{*}{ E. $\operatorname{tar} d a$} \\
\hline & & & $10^{6}$ & $10^{5}$ & $10^{4}$ & $10^{3}$ & $10^{2}$ & $10^{1}$ & \\
\hline \multirow[t]{6}{*}{$4 \mathrm{CIN}$} & \multirow[t]{2}{*}{24} & 1. $x$ & + & + & + & + & - & - & - \\
\hline & & $2 \times$ & + & + & + & + & + & + & + \\
\hline & \multirow{2}{*}{36} & $1 \times$ & + & + & + & + & - & - & - \\
\hline & & $2 x$ & + & + & + & + & \pm & + & \pm \\
\hline & \multirow[t]{2}{*}{48} & $1 \times$ & + & + & \pm & - & - & - & - \\
\hline & & $2 x$ & + & + & + & + & + & + & \pm \\
\hline \multirow[t]{6}{*}{$\mathrm{DAB}$} & \multirow[t]{2}{*}{24} & $1 \times$ & + & + & + & + & + & + & - \\
\hline & & $2 \times$ & + & + & + & + & + & + & \pm \\
\hline & \multirow[t]{2}{*}{36} & $1 \times$ & + & + & + & + & + & + & - \\
\hline & & $2 x$ & + & + & + & + & $t$ & + & \pm \\
\hline & \multirow[t]{2}{*}{48} & $1 \times$ & + & + & + & + & + & + & - \\
\hline & & $2 \times$ & + & + & + & + & + & + & \pm \\
\hline
\end{tabular}


and ventral region of the head and lesions in the cartilage of nares and cranial fontanelle. Agar cultures of Edwardsiella ictaluri were obtained from 7 of the 9 clinically diseased fish whereas filter cultures of $E$. ictaluri were obtained from all 9 of these fish. No clinical signs of ESC were evident among 89 of the sampled fish, however, E. ictaluri was isolated from $21(24 \%)$ of these asymptomatic fish by standard necropsy methods on EIM isolations, and from 71 fish (80\%) using tissue homogenization, filtration and ELISA (Table 4).

\section{DISCUSSION}

Modifications from the ELISA and filtration procedures of Lee (1989) were required because that assay only had to render Renibacterium salmoninarum recognizable for filter microscopy rather than culture viability. Some of these modifications, namely the addition of detergents or enzymes to the homogenates, improved filtration and bacterial recovery. The addition of Triton X-100 $(0.5 \%)$ to the tissue of channel catfish infected with Edwardsiella ictaluri for homogenization improved their filterability and the recovery of bacteria was equal to or better than PBS without supplementation. It also allowed filtration of approximately $1 \mathrm{~g}$ of tissue homogenate while producing manageable levels of foam. Tween 20 moderately improved filterability and only slightly improved bacterial recovery but the homogenates did not clear. Trypsin did not improve filterability and recovery of bacteria was markedly less than that of PBS. Because of variable bacterial counts in the tissue samples, conclusions were based on qualitative observations (Table 1). Under the range of homogenization procedures tested, $0.5 \%$ Triton $\mathrm{X}-100$ in combination with $1 \times$ secondary monoclonal E. ictaluri antibody was qualitatively superior to all other treatments.

Triton X-100 increased bacterial recovery as much as 7 to $12 \%$ over homogenization in unsupplemented PBS (Table 2). It appears the detergent treatments caused increased CFU counts through rupture of host cells and dispersal of packed bacteria in fresh, infected tissues. During refrigerated storage, macrophages may have ruptured as part of postmortem change, rendering detergent-mediated bacterial dispersion unnecessary. This is consistent with observations of Hanson \& Rogers (1989) that upon death, macrophages of infected fish rupture, thus allowing dispersal of Edwardsiella ictaluri. The use of $0.5 \%$ Triton $\mathrm{X}-100$ as homogenization solution means either fresh or refrigerated samples may be assayed without affecting bacterial abundance.

The combination of an extended culture incubation period, the DAB stain, and transmitted light optimized
Edwardsiella ictaluri colony counts using filter ELISA. while colonies of E. tarda remained negative. Microscopic verification and semipermanent records of the tissue screening are also possible with DAB. Rapid colony counts exceeding 500 CFU per plate are possible using an ordinary or electronic counting probe to puncture colonies as they are counted (Earlix 1995). The technique is far superior to microscopic filter counts in all respects.

Modification of filtration apparatus would likely improve filter ELISA tissue counts. A filtration bed modified for $85 \mathrm{~mm}$ filters was used in this study, but standard $47 \mathrm{~mm}, 0.45 \mu \mathrm{m}$ membrane filters would have worked equally well because bacterial overgrowth is not a limiting factor as it is for environmental bacterial counts. Further, such an apparatus could utilize a $3 \mu \mathrm{m}$ nylon prefiltration pad used by Lee (1989) that would trap incompletely homogenized tissues which could compromise recovery. The expected increase in filtration capacity could lower detection thresholds further by allowing filtration of complete homogenized organs of adult fish or multiple organs from juveniles. The variation in bacterial abundance in host organ tissues, encountered in the homogenization treatment experiment, emphasizes the importance of large tissue samples for low number bacterial detection protocols.

Primary bacteriological isolation from clinically infected fish can generally be accomplished satisfactorily with loop inoculation of agar medium. Failure to isolate bacteria by conventional necropsy from 2 out of 9 clinically diseased fish in this study illustrates the difficulty of a screening procedure relying on tissue sample size as small as 1 inoculating loop full (about $20 \mu \mathrm{g}$ ); however, because standard bacterial detection procedure dictates the testing of multiple fish (Thoesen 1994), occasional isolation failure among clinically infected fish is not problematic. The use of EIM agar enhances Edwardsiella ictaluri isolation when multiple infections exist. Aeromonas hydrophila was found to co-infect fish suffering from ESC (Hanson \& Grizzle 1985, Antonio \& Hedrick 1994) and may overgrow and mask $E$. ictaluri on a nonselective agar.

Standard bacteriological screening failed to detect about $2 / 3$ of the asymptomatic fish infected with $E d$ wardsiella ictaluri. Although it is not possible to determine true E. ictaluri infection prevalence from this study, direct microscopic examination failed to uncover any false positive ELISA colony labeling. Therefore, the $80 \%$ infection prevalence among the sampled asymptomatic fish shown by filter ELISA is a reliable minimum figure for a diseased population with some fish expressing clinical signs of ESC. The $24 \%$ prevalence suggested by standard bacteriological examination is a gross underestimation. 
Through lack of evidence to the contrary. Edwardsiella ictaluri prevalence has generally been thought to be low in asymptomatic populations, ranging from $5 \%$ during the growing season to $1 \%$ in winter (Shotts \& Plumb 1994). Field monitoring in west Alabama, USA, commercial channel catfish ponds used diagnostic bacteriology to show infection prevalence of up to $8 \%$ (Earlix 1995). The results of filter ELISA suggest prevalence may exceed this figure by at least a factor of 10 . If asymptomatically infected fish populations have infection skewed strongly towards lower infection intensity (Martin 1987), and bacteriological isolation represents only heavily infected fish, it is conceivable that conventional bacteriology may detect less than $10 \%$ of infected fish among a clinically healthy, but infected population

Conventional diagnostic bacteriology has been avoided for Edwardsiella ictaluri carrier studies in the past. Mgolomba \& Plumb (1992) homogenized entire organs to perform counts of bacteria to show juvenile channel catfish harbored E. ictaluri for $81 \mathrm{~d}$ after experimental infection. Unfortunately, the study was limited by the absorptive capacity of agar and the sample size permitted by the microdrop technique; therefore, the resulting $25 \mu \mathrm{g}$ of diluted tissue sampled would be unlikely to detect many low grade infections. Also, Klesius (1992) incubated the entire kidney from channel catfish fingerlings in EIM broth to detect E. ictaluri. While not quantitative, the use of whole organs may be ideal for screening carriers with validation by the methods described here.

This study shows that incorporation of an ELISA, using a monoclonal antibody with filtration of detergent treated tissue homogenates, can be used to detect a high prevalence of Edwardsiella ictaluri infection in channel catfish. The filter-enzyme procedure is superior to conventional bacteriological isolation methods of assaying possible carrier fish.

Acknowledgements. The research was supported by the U.S. Fish and Wildlife Service Grant No. FWS-141600091550-34A and the Southeastern Cooperative Fish Disease Project. Thanks are expressed to C. J. Ashfield for providing infected fish and assisting in bacterial isolation.

Responsible Subject Editor: D. W. Bruno, Aberdeen, United Kingdom

\section{LITERATURE CITED}

Antonio DB, Hedrick RP (1994) Effects of the corticosteroid Kenalog on the carrier state of juvenile channel catfish exposed to Edwardsiella ictaluri. J Aquat Anim Health 6:44-52

Chen MF, Henry-Ford D, Kumlin ME, Light TS (1994) The distribution of Edwardsjella ictaluri in California. J Aquat Anim. Health 6:234-231

Earlix DJ (1995) Host, pathogen, and environmental interactions of enteric septicemia of catfish. PhD dissertation, Auburn University, AL

Hanson LA, Grizzle JM (1985) Nitrite-induced predisposition of channel catfish to bacterial diseases. Prog Fish-Cult 47: 98-101

Hanson LA, Rogers WA (1989) Enzyme immunoassay identification of Edwardsiella ictaluri in decomposing channel catfish. J World Aquacult Soc 20:279-280

Jones JG. Simon BM (1975) An investigation of errors in direct counts of aquatic bacteria by epifluorescence microscopy, with reference to a new method for dyeing membrane filters. J Appl Bacteriol 39:317-329

Klesius PH (1992) Carrier state of channel catfish infected with Edwardsiella ictaluri. I Aquat Anim Health 4:227-230

Lee EGH (1989) Techniques for enumeration of Renibacterium salmoninarum in fish kidney tissues. J Aquat Anim Health $1: 25-28$

MacMillan JR (1985) Infectious disease. In: Tucker CS (ed) Channel catfish culture. Elsevier, Amsterdam, p 405-496

Martin WS (1987) Veterinary epidemiology: principles and methods. Iowa State University Press, Ames, IA

Mgolomba TN, Plumb JA. (1992) Longevity of Edwardsiella ictaluri in the organs of experimentally infected channe] catfish, Ictalurus punctatus. Aquaculture 101:1-6

Shotts EB, Blazer VS, Waltman WD (1986) Pathogenesis of experimental Edwardsiella ictaluri infections in channel catfish (Ictalurus punctatus). Can J Fish Aquat Sci 43: $36-42$

Shotts EB Jr, Plumb JA (1994) Enteric Septicemia (VIII). In: Thoesen JC (ed) Suggested procedures for the detection and identification of certain finfish and shellfish pathogens, 4 th edn. Fish Health Section, American Fisheries Society. SOS Publication, Fair Haven, NJ, p 1-3

Shotts EB, Waltman WD II (1990) A medium for the selective isolation of Edwardsiella ictaluri. J Wildl Dis 26:214-218

Taylor PW (1992) Fish-eating birds as potential vectors of Edwardsiella ictaluri. J Aquat Anim Health 4:240-243

Thoesen JC (1994) Suggested procedures for the detection and identification of certain finfish and shellfish pathogens, 4 th edn. Fish Health Section, American Fisheries Society. sos Publication, Fair Haven, NJ

Wiebe WJ (1971) Perspectives in microbial ecology. In: Odum ED (ed) Fundamentals of ecology, 3rd edn. Saunders College Publishing, Philadelphia, PA, p 489-497

Manuscript first received: December 29, 1995

Revised version accepted: April 29, 1996 